\title{
Down-regulation of MicroRNA-126 in Glioblastoma and its Correlation with Patient Prognosis: A Pilot Study
}

\author{
IN BO HAN ${ }^{1,6}$, MINSOO KIM ${ }^{2}$, SOO HONG LEE ${ }^{3}$, JIN KWON KIM ${ }^{4}$, \\ SE HOON KIM ${ }^{5}$, JONG HEE CHANG ${ }^{2}$ and YANG D. TENG ${ }^{6,7}$ \\ ${ }^{1}$ Department of Neurosurgery, ${ }^{4}$ Department of Neurology, CHA University, \\ Bundang CHA Medical Center, Gyeonggido, Republic of Korea; \\ ${ }^{2}$ Department of Neurosurgery, Brain Tumor Center, and Brain Research Institute, \\ Yonsei University Health System, Seoul, Republic of Korea; \\ ${ }^{3}$ Department of Biomedical Science, CHA University, Gyeonggido, Republic of Korea; \\ ${ }^{5}$ Department of Pathology, Severance Hospital, Yonsei University Health System, Seoul, Republic of Korea; \\ ${ }^{6}$ Departments of Physical Medicine \& Rehabilitation and Neurosurgery, Harvard Medical School, \\ Spaulding Rehabilitation Hospital and Brigham \& Women's Hospital, Boston, MA, U.S.A.; \\ ${ }^{7}$ Division of SCI Research, Veterans Affairs Boston Healthcare System, West Roxobury, MA, U.S.A.
}

\begin{abstract}
Glioblastoma is the most common primary malignant tumor of the adult human brain. Although microRNA-126 (miR-126) has been reported to exhibit expression abnormalities in various types of cancer, to date very few studies have examined changes in miR-126 level in glioblastoma. In this pilot study, we investigated the changes in miR-126 expression in newly-dissected primary glioblastoma to explore possible roles of miR-126 in patient prognosis. Total RNA was extracted from tumoral and adjacent non-cancerous tissues from 14 patients' paired frozen specimens. Using an established quantitative reverse transcriptase-PCR protocol, the levels of miR-126 in glioblastoma and adjacent non-tumor brain tissues were compared against small nucleolar RNA U48 (RNU48) as a reference gene. The expression of miR-126 in glioblastoma samples was significantly lower than in paired non-tumoral controls $(p<0.05)$. Importantly, age-adjusted analyses suggest that glioblastoma patients with higher relative intratumoral
\end{abstract}

Correspondence to: Yang D. Teng, MD, Ph.D., Departments of PM\&R and Neurosurgery, Harvard Medical School/Division of Spinal Cord Injury Research, Veterans Affairs Boston Health Care System, 221 Longwood Avenue, Boston, Massachusetts 02115, U.S.A. E-mail: yang_teng @hms.harvard.edu or Jong Hee Chang MD, Ph.D., Department of Neurosurgery, Brain Tumor Center, and Brain Research Institute, Yonsei University Health System, 50 Yonsei-ro, Soedaemun-gu, Seoul 03722, Korea. Tel: +82 222282162, Fax: +82 23939979, e-mail: changjh@yuhs.ac

Key Words: Glioblastoma, microRNA, miR-126, prognosis, RT-PCR, cancer stem cell.
miR-126 expression (i.e. 53-79\% relative to that of the control tissue; $n=7)$ had significantly improved survival duration than patients whose miR-126 levels were lower (i.e. 12-48\%, $n=7$; stratified log-rank analysis $p=0.011$ when the dividing threshold was set at $\geq 51 \%$; total: $n=14$, male: 8 ; female: 6$)$. Thus, intraglioblastoma miR-126 may be down-regulated relative to normal tissue and patients with less downregulation of intratumoral miR-126 expression could have improved postsurgical prognosis. Future clinical studies with larger sample sizes should be performed to validate this observation.

Glioblastoma is the most common and aggressive primary malignant brain tumor in humans (1). Despite considerable advances in therapy development, including imaging-guided surgical techniques, radiation and chemotherapy, more than $90 \%$ of glioblastoma patients die within 3 years of diagnosis and the precise mechanisms of glioblastoma carcinogenesis remain unclear. In order to develop better diagnostic, therapeutic, and prognostic tools for glioblastoma, enhancement for molecular level understanding of the disease is crucial. Due to their powerful regulatory capabilities, microRNAs (miRNAs) are being actively investigated as diagnostic and prognostic biomarkers as well as therapeutic targets for a wide variety of diseases (2).

miRNAs are small single-stranded, non-coding RNAs that can modulate protein expression by regulating translation efficiency or cleavage of their target mRNAs. They play crucial roles in regulation of essential biological processes including cell proliferation, cell differentiation, and apoptosis $(2,3)$. There is increasingly appreciated 
evidence that numerous miRNAs are involved in glioblastoma carcinogenesis and tumor growth $(2,3)$. Hence, obtaining better knowledge about biological mechanisms of miRNAs involved in glioblastoma oncogenesis may provide a new platform for improving the diagnosis, assessment of tumor staging and progression, evaluation of patient prognosis, and determination of treatment strategies for tackling this disease.

Data are emerging that $m i R-126$ is an important player in endothelial cell biology and tumor angiogenesis that is a hallmark event of cancer progression (Figure 1A) $(4,5)$. Interestingly, $m i R-126$ was initially reported to function as an oncogene; however, several studies have shown that $m i R$ 126 is down-regulated in different cancer cells and could work as a potential tumor suppressor. For example, whereas it was up-regulated in acute myeloid leukemia, $m i R-126$ was shown to be down-regulated in osteosarcoma, and cervical, lung, gastric, and colorectal cancer (6-10). These diverse findings suggested that miR-126 may have multiple functions that might be tissue- or disease-specific. To date, the clinical oncological impact of $m i R-126$ on glioblastoma and putative links between miR-126 expression and glioblastoma pathology has not been systematically reported. We hypothesized that miR-126 may participate in glioblastoma tumorigenesis processes and tested this by first comparing the expression levels of $m i R-126$ in glioblastoma compared to adjacent non-cancerous tissue of the same patient using quantitative reverse transcription-polymerase chain reaction (qRT-PCR) analysis. The result was then correlated with the post-gross total resection survival data of each sample donor patient to determine the value of prognosis assessment.

\section{Materials and Methods}

This was a prospective study of patients with glioblastoma based on comparison of miR-126 expression between surgically removed tumor mass and adjacent non-cancerous parenchyma samples. Informed consent was obtained from all patients involved and the Institutional Review Board of the Bundang CHA Medical Center approved all protocols of the study (IRB Protocol number: BD2014-050).

Study subjects. Fourteen patients with primary glioblastoma who underwent maximal safe surgical resection (i.e. gross total resection) participated in the study based on the following inclusion criteria. Tumor was removed with a wide tumor-free resection margin of 2 $\mathrm{cm}$. Prior to surgery, the Karnofsky performance score (KPS) was evaluated and bidimensional tumor measurements were made based on contrast-enhanced T1-weighted magnetic resonance imaging. Surgery was the first-line treatment and none of the patients underwent radiotherapy or chemotherapy prior to the surgery. All patients underwent gross total resection of the tumor followed by our standard irradiation treatment and chemotherapy. Briefly, the radiotherapy component consisted of fractionated focal irradiation at a dose of 2 Gy per fraction given once a day, 5 days a week, for a period of 6 weeks, for a total dose of $60 \mathrm{~Gy}$, together with temozolomide administration $\left(75 \mathrm{mg} / \mathrm{m}^{2} / \mathrm{day}, 7\right.$ days/week) from the

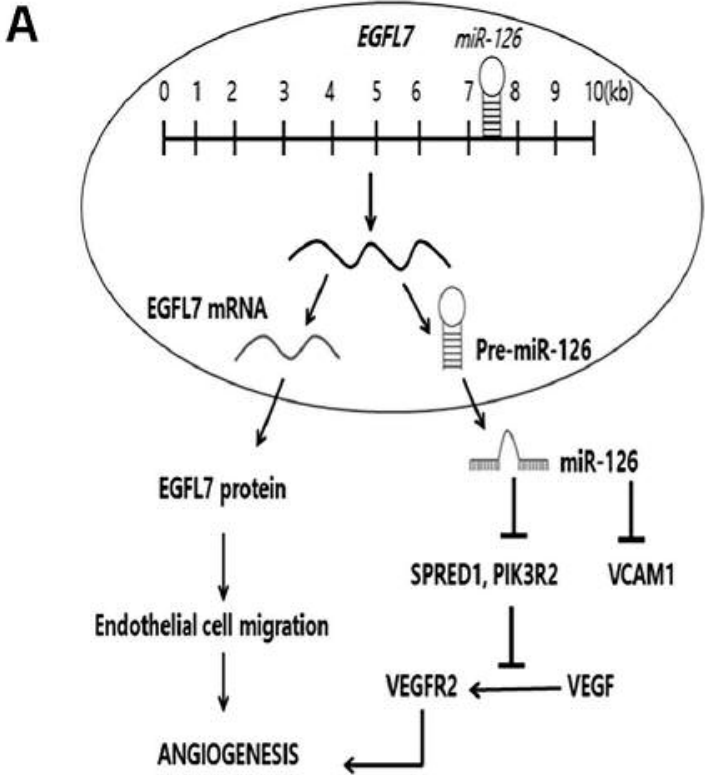

B

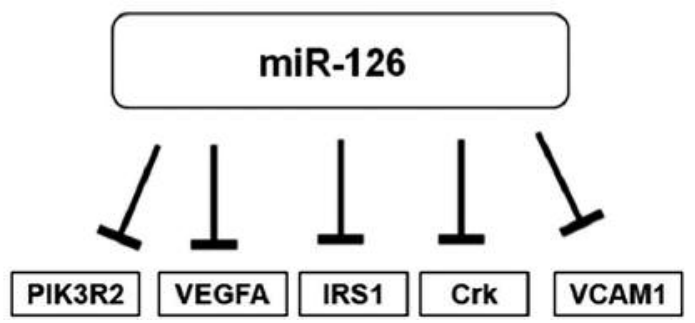

Figure 1. A: MicroRNA-126 (miR-126) and its host gene, epidermal growth factor-like domain 7 (EGFL7). miR-126 and EGFL7 are co-transcribed from human chromosome 9. EGFL7 induces endothelial cell migration, whereas miR-126 enhances vascular endothelial growth factor (VEGF)dependent angiogenesis by inhibiting the expression of sprouty-related, Drosophilia enabled/vasodilator-stimulator phosphoprotein homology 1 (EVH1) domain-containing protein 1 (SPRED1) and phosphoinositide-3kinase, regulatory subunit 2 (PIK3R2). B: Regulatory networks of miR126 as a tumor suppressor. miR-126 may act as a tumor suppressor via the inhibition of proliferation, migration, and invasion of cancer cells through acting on targets of insulin receptor substrate 1 (IRS1) and v-Crk sarcoma virus CT10 oncogene homolog (Avian) proteins (CRK); it may also block signaling pathways that govern angiogenesis, vascular integrity (e.g. PIK3R2, VEGFA) and inflammation (e.g. VCAM-1: vascular cell adhesion molecule). VEGFR: Vascular endothelial growth factor receptor.

first to the last day of radiotherapy (or with an additional treatment that was no longer than 49 days). Temozolomide was administered daily 1 hour before radiotherapy or in the morning on days without radiotherapy. After a 4-week break, the patient received up to six cycles of adjuvant temozolomide, according to a standard 5-day schedule, every 28 days. The telozolomide dose was $150 \mathrm{mg} / \mathrm{m}^{2} /$ day for the first cycle, and it was increased to $200 \mathrm{mg} / \mathrm{m}^{2} /$ day at the beginning of the second cycle if no hematological toxicity was observed. 
Table I. Clinical characteristics and relative miR-126 expression levels in cancer tissues.

\begin{tabular}{lccccccc}
\hline Gender & $\begin{array}{c}\text { Age } \\
\text { (years) }\end{array}$ & $\begin{array}{c}\text { Tumor } \\
\text { location }\end{array}$ & $\begin{array}{c}\text { Tumor } \\
\text { size }(\mathrm{cm})\end{array}$ & $\begin{array}{c}\text { Karnofsky performance } \\
\text { (score) }\end{array}$ & $\begin{array}{c}\text { Last follow-up } \\
\text { status }\end{array}$ & $\begin{array}{c}\text { Survival time } \\
\text { (months) }\end{array}$ & $\begin{array}{c}\text { Relative miR-126 } \\
\text { expression level }\end{array}$ \\
\hline M & 48 & Parietotemporal & 6.6 & 70 & Dead & 30 & 0.39 \\
M & 39 & Frontal & 6.2 & 80 & Dead & 12 & 0.12 \\
M & 59 & Frontal & 6.4 & 80 & Alive & 53 & 0.56 \\
M & 47 & Central & 4.5 & 80 & Alive & 58 & 0.76 \\
F & 33 & Parietotemporal & 4.4 & 100 & Alive & 57 & 0.53 \\
F & 56 & Frontal & 6.4 & 80 & Alive & 54 & 0.63 \\
F & 30 & Parietotemporal & 5.5 & 70 & Dead & 15 & 0.36 \\
M & 43 & Frontal & 5.7 & 80 & Alive & 56 & 0.60 \\
F & 30 & Parietotemporal & 5.1 & 90 & Alive & 46 & 0.48 \\
F & 49 & Parietotemporal & 4.8 & 9.3 & Alive & 54 & 0.58 \\
M & 63 & Frontal & Dead & Dead & 4 & 0.30 \\
F & 53 & Frontal & 4.9 & 70 & Alive & 56 & 0.32 \\
M & 44 & Frontal & 6.1 & 90 & Dead & 14 & 0.79 \\
M & 67 & Frontal & 6.3 & 70 & & 0.27 \\
\hline
\end{tabular}

M: Male. F: Female.

For each patient, tumor tissue was collected from the main bulk of the tumor tissues and peritumoral non-cancerous tissue sampled $3 \mathrm{~cm}$ from the border line of the tumor. All paired samples were examined by a board-certified neuropathologist (S.H.K) and were snap-frozen in liquid nitrogen immediately after surgical removal and subsequently stored at $-80^{\circ} \mathrm{C}$ until qRT-PCR analysis. The diagnosis of glioblastoma was confirmed according to the current World Health Organization (WHO) classification of the central nervous system tumors (11).

Quantitative reverse transcriptase-polymerase chain reaction ( $q R T$ $P C R$ ). Total RNA was isolated from brain tissue by TRIzol (Invitrogen, Carlsbad, CA, USA) according to the manufacturer's instructions. The concentration was quantified using a NanoDrop 1000 Spectrophotometer (Thermo Fisher Scientific, Wilmington, DE, USA). Expression of $m i R-126$ was analyzed with qRT-PCR performed using TaqMan microRNA assays (Applied Biosystems, Foster City, CA, USA) as previously described for human lung cancer tissues (24). Small nucleolar RNA U48 (RNU48) (Applied Biosystems) was used as the reference gene for calculating the expression ratio of $m i R-126$ (25). For this pilot study, all procedures were performed in duplicate and the expression of $m i R-126$ was expressed as $\Delta \mathrm{Ct}$. The $\Delta \mathrm{Ct}$ value was the difference between the $\mathrm{Ct}$ value of $m i R-126$ and that of $R N U 48$. The $\Delta \Delta \mathrm{Ct}$ value was the difference between the $\Delta \mathrm{Ct}$ value of glioblastoma tissues and the $\Delta \mathrm{Ct}$ value of non-cancerous tissue. The value of $2^{-\Delta \mathrm{Ct}}$ was $m i R-126$ expression or content of each sample and the value of $2^{-\Delta \Delta C t}$ represented the expression ratio of $m i R-126$ in glioblastoma tissue versus that of adjacent non-tumor tissue. A value of $2^{-\Delta \Delta \mathrm{Ct}}<1$ indicates that the expression of miRNA in cancerous tissues was lower than that in non-tumor tissue.

Statistical analysis. SPSS (Statistical Package for Social Sciences, version 21; IBM Corp., Armonk, NY, USA) was used for all statistical analyses. Paired $t$-test was performed to compare folddifferences in $m i R-126$ expression between tumors and adjacent non-tumor tissues with $p<0.05$ considered statistically significant. In order to evaluate the prognostic value of the intratumoral expression level of $m i R-126$, we tested the hypothesis of whether the intratumoral level of $m i R-126$ is correlated with postsurgical patient survival. Survival curves were constructed using the standard Kaplan-Meier method. Stratified log-rank test was used to test differences in survival time between two subgroups of patients for whom the intratumoral $m i R-126$ expression of $\geq 53 \%$ relative to the control tissue was set as the threshold to divide "less reduced" versus "further reduced" expression groups. Please see respective Results section below for additional statistical analyses used.

\section{Results}

Demographic data and survival. Demographic and survival data of the patients are detailed in Table I. There were eight male and six female patients whose median age was 47 years (range $=30-67$ years). The median KPS was 80 (range $=70$ 100). The glioblastomas were located in the frontal lobe in eight patients, the parieto-temporal lobe in five and central lobe in one patient. At the last follow-up evaluation, eight patients were still alive, which resulted in a median survival time of 54 (range=46-58) months. By contrast, the median survival time of the six patients who had died was 10 (range=4-30) months .

Using univariate analysis, we determined that gender, age, pre-surgery KPS, tumor size and tumor location were not significantly correlated with postsurgical survival time for this group of patients. The outcome further validated our study design that was aimed to explore possible prognostic roles of $m i R-126$ for glioblastoma patients postsurgery.

Down-regulation of miR-126 in glioblastoma. By qRT-PCR, the expression of $m i R-126$ in the glioblastoma tissues from 14 patients was compared with that in the paired non-tumor brain tissues. We found that all glioblastoma tissues 
exhibited significantly lower miR-126 expression than the corresponding non-tumor tissues (Figure 2A). The highest (i.e. the least reduced) expression was 0.79 (patient number \#13) and the lowest (i.e. most reduced) expression was 0.12 (patient number \#2), relative to the non-tumor control tissue level of $m i R-126$ expression (set as 1.00).

Table II shows the $\mathrm{Ct}$ values of $m i R-126$ obtained from cancerous mass and adjacent non-cancerous parenchyma from the enrolled patients. The $\Delta \mathrm{Ct}$ values of miR-126 of non-cancerous tissue and cancerous tissue and the $\Delta \Delta \mathrm{Ct}$ and $2^{-\Delta \Delta C t}$ values were calculated based on formulas described in the Materials and Methods. Overall, the miR-126 content was also discernibly lower in the glioblastoma tissues compared to non-cancerous controls for the same patients. Specifically, the average $\Delta \mathrm{Ct}$ and the average $2^{-\Delta \mathrm{Ct}}$ ( $m i R-126$ content) for glioblastoma and non-cancerous tissues were -1.465 and -2.717 , and 2.760 and 6.575 , respectively. The $2^{-\Delta \Delta C t}$ values of $m i R-126$ were less than 1.0 , indicating that expression levels of miR-126 in glioblastoma tissue were lower than those in non-tumor tissue (Figure 2B).

Relationship between the expression of miR-126 and the clinical pathophysiological features of glioblastoma. Associations between the content of miR-126 in glioblastoma tissues and clinical pathophysiological parameters were analyzed by the Mann-Whitney $U$-test. Decreased content of $m i R-126$ in glioblastoma was not associated with gender, age, presurgical KPS, tumor size, nor tumor location.

We further analyzed the overall postsurgical survival data of patients with glioblastoma and correlated the outcomes with the corresponding intratumoral miR-126 expression levels. We found a significant correlation between the overall survival duration and the expression level of intratumoral miR-126. Based on the Kaplan-Meier longevity curve of the patients determined in the last follow-up, stratified log-rank analysis showed that there was a significant positive correlation between the relative expression level of miR-126 and the patient's survival outcome. Importantly, there was a highly significant improvement in postsurgical survival for patients with less reduced levels of $m i R-126$ (i.e. $0.79 \geq m i R-126 \geq 51 \%$ relative to adjacent normal tissue, as determined by stratified log-rank analysis when $p=0.011$; total: $\mathrm{n}=14$ ) after adjustment for patient age (Figure 3). The data suggest that glioblastoma patients with higher (i.e. less reduced) relative expression of miR-126 may live longer after gross total resection of the tumor plus standard radiochemotherapy than patients who have more greatly reduced intratumoral miR-126 levels.

\section{Discussion}

The main findings of this pilot study are that $m i R-126$ may be down-regulated in glioblastoma tissue relative to noncancerous parenchyma obtained from the peritumoral area of
Table II. $C t, \Delta C t$ and $2^{-\Delta C t}$ values of miR-126 expression in glioblastoma tissue and adjacent non-tumor tissue.

\begin{tabular}{|c|c|c|c|c|c|c|c|c|}
\hline \multirow[b]{2}{*}{ Case no. } & \multicolumn{2}{|c|}{$m i R-126$} & \multicolumn{2}{|c|}{$R N U 48$} & \multicolumn{2}{|c|}{$\Delta \mathrm{Ct}$} & \multirow[b]{2}{*}{$\Delta \Delta \mathrm{Ct}$} & \multirow[b]{2}{*}{$2^{-\Delta \Delta C t}$} \\
\hline & Tumor & NTT & Tumor & NTT & Tumor & NTT & & \\
\hline 1 & 23.55 & 24.46 & 24.59 & 27.23 & -1.04 & -2.77 & 1.73 & 0.3014 \\
\hline 2 & 24.86 & 23.16 & 25.10 & 26.50 & -0.24 & -3.34 & 3.10 & 0.1166 \\
\hline 3 & 22.53 & 22.36 & 23.84 & 24.49 & -1.31 & -2.13 & 0.82 & 0.5664 \\
\hline 4 & 22.47 & 23.15 & 24.25 & 25.54 & -1.78 & -2.39 & 0.61 & 0.6551 \\
\hline 5 & 22.34 & 22.13 & 25.06 & 25.73 & -2.72 & -3.60 & 0.88 & 0.5433 \\
\hline 6 & 18.52 & 24.57 & 21.23 & 27.79 & -2.71 & -3.22 & 0.51 & 0.7022 \\
\hline 7 & 23.31 & 23.73 & 24.37 & 26.52 & -1.06 & -2.79 & 1.73 & 0.3014 \\
\hline 8 & 23.03 & 22.60 & 24.14 & 24.47 & -1.11 & -1.87 & 0.76 & 0.5904 \\
\hline 9 & 28.60 & 23.68 & 30.03 & 25.90 & -1.43 & -2.22 & 0.79 & 0.5783 \\
\hline 10 & 26.26 & 23.36 & 28.03 & 25.86 & -1.77 & -2.50 & 0.73 & 0.6029 \\
\hline 11 & 23.64 & 23.20 & 24.17 & 25.47 & -0.53 & -2.27 & 1.74 & 0.2993 \\
\hline 12 & 23.45 & 20.98 & 25.02 & 24.22 & -1.57 & -3.24 & 1.67 & 0.3142 \\
\hline 13 & 25.56 & 22.34 & 28.01 & 25.23 & -2.45 & -2.89 & 0.44 & 0.7371 \\
\hline 14 & 25.93 & 22.63 & 26.72 & 25.44 & -0.79 & -2.81 & 2.02 & 0.2465 \\
\hline
\end{tabular}

NTT: non-tumor tissue; RNU48: small nucleolar RNA U48.

the same patient and patients may have differential expression of intra-glioblastoma $m i R-126$. Furthermore, patients with primary glioblastoma characterized by more severely reduced $m i R-126$ expression displayed poorer postsurgical survival as compared to patients with glioblastoma that exhibited less reduction of $m i R-126$ expression. The data suggest that there might be a negative correlation between the loss of intratumoral miR-126 expression and general survival gain of patients with primary brain glioblastoma following gross total resection and standard chemotherapy.

Our preliminary finding concerning intra-glioblastoma $m i R-126$ level is consistent with published data in which down-regulation of miR-126 in cancerous versus noncancerous tissues was determined in a variety of human malignancies, including osteosarcoma and cervical, lung, gastric and colorectal cancer (6-10). Interestingly, analysis of the miRNA expression data of glioblastoma patients in The Cancer Genome Atlas's dataset (cancergenome.nih.gov) suggested that there were eight risky miRNAs (i.e. $m i R-148 a$, miR-31, miR-26a, miR-222, miR-221, miR-146b, miR-200b, and $m i R-193 a)$ and three protective miRNAs (miR-20a, $m i R$ $106 a$, and $m i R-17-5 p$ ), without implementing $m i R-126$ (1214). However, a more recent investigation of tissue bank samples revealed that the expression of miR-126 was indeed significantly down-regulated in glioma tissues compared to that in normal controls; moreover, high-grade gliomas had even lower expression of $m i R-126$ relative to that of lowgrade tumors (15). The published data derived from a direct comparison between glioblastoma and healthy brains corroborated our results that measured intratumoral $m i R-126$ level relative to self-control normal tissue of the same brain. 

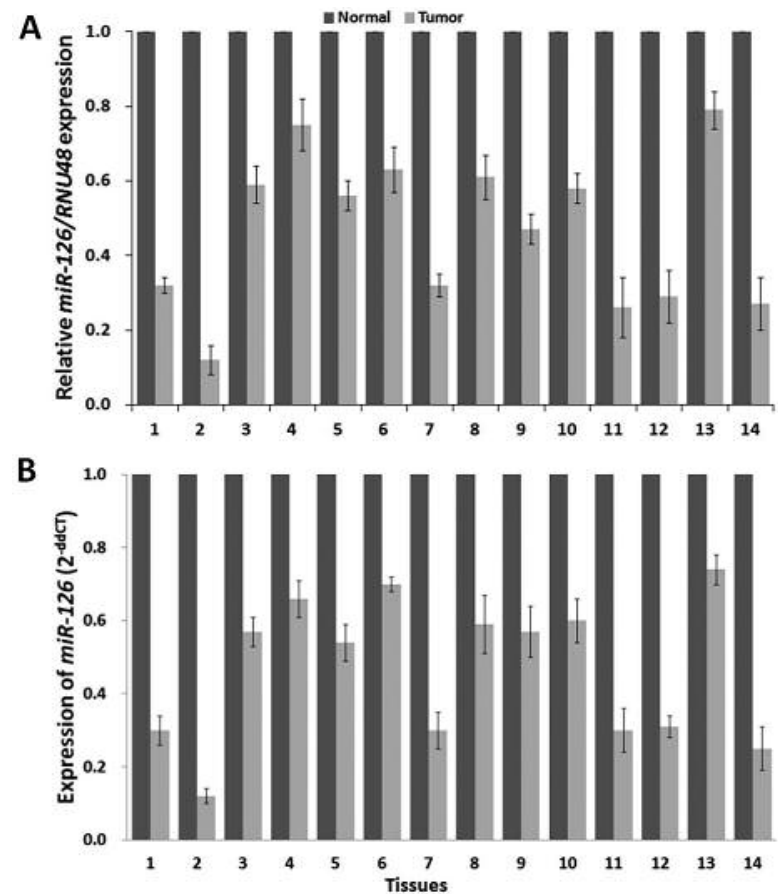

Figure 2. A: miR-126 expression level as determined by quantitative reverse transcription-polymerase chain reaction ( $q R T-P C R)$. Expression of miR-126 was measured in 14 glioblastoma tissues and their paired nontumor parenchymal samples by qRT-PCR. The expression levels of glioblastoma tissues were independently compared to those of the paired non-tumor tissues, which were normalized to 1. B: Value of $2^{-\Delta \Delta C t}$ of miR126. All $2^{-\Delta \Delta C t}$ values of miR-126 for paired samples of the patients were less than 1.0, showing that expression levels of miR-126 in glioblastoma tissues were lower than that in non-tumor control specimens. Data are means \pm difference ranges between the two measurements.

$m i R-126$ has been shown to be either a tumor suppressor or an oncogene depending on the type of cancer, with the exact mechanisms in various cancer types still under intensive investigation. Various molecular signal cascades affecting cancer cell growth have now been confirmed for their regulation by $m i R-126$. As examples, $m i R-126$ can inhibit tumor cell growth through directly targeting p85- $\beta$ (encoded by $P I K 3 R 2)$ and insulin receptor substrate 1 (IRS1) in colon cancer cell lines and HEK293 and MCF-7 cells, respectively (16-18). Down-regulation of vascular endothelial growth factor A (VEGF-A) by miR-126 triggers cell-cycle arrest of lung cancer cells both in vitro and in vivo (19). Additionally, tumor-suppressive effect of $m i R-126$ has been suggested to be partially mediated by down-regulation of v-Crk sarcoma virus CT10 oncogene homolog (avian) proteins $(C R K)$ and vascular cell adhesion molecule 1 (VCAMI), which are overexpressed in cancer cells (Figure 1B) (20). Conversely, $m i R-126$ has been suggested to be an oncomiR, playing a role in promoting angiogenesis in response to VEGF and basic

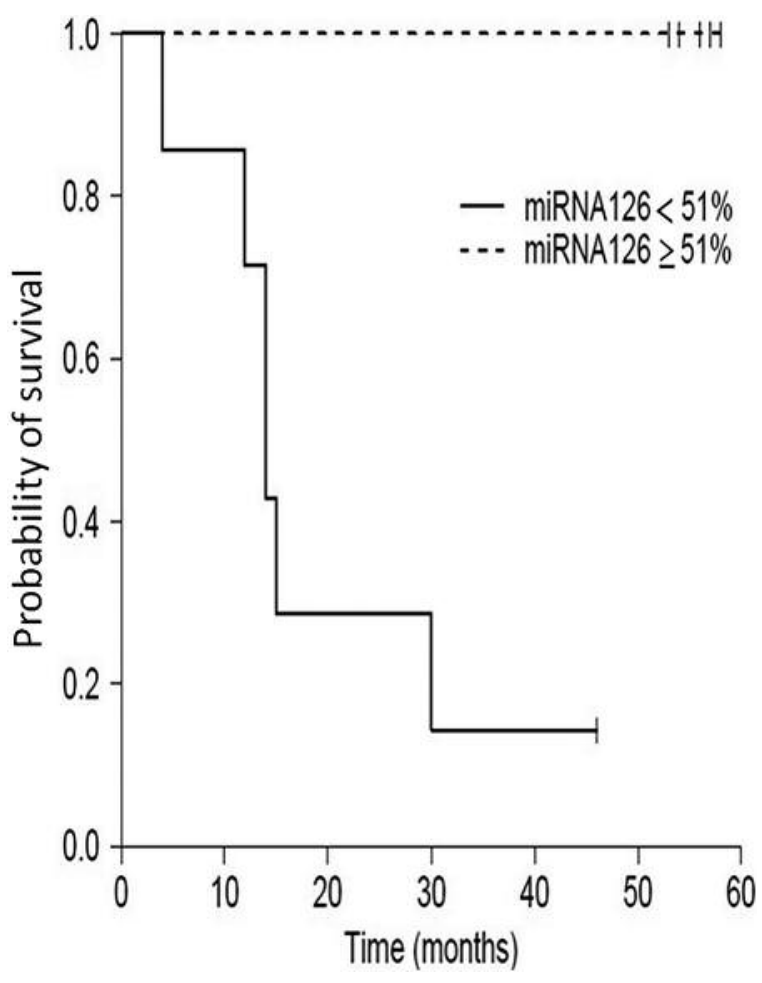

Figure 3. Survival analysis by log-rank test. The log-rank tests stratified patients by their age. Kaplan-Meier longevity curve analysis showed a highly significant correlation between miR-126 expression ratio (i.e. intratumoral levels relative to control non-tumoral tissues, set as 100\%) and duration of patient survival. Post-treatment survival for patients who had a significantly higher relative intra-tumoral miR-126 expression ( $\geq 51 \%: 51-79 \%$ ) was significantly longer than those with a lower miR126 expression ratio (stratified log-rank test, $p=0.011 ; n=14$ ).

fibroblast growth factor (bFGF or FGF2) through repressing negative suppressors in the signal transduction pathways (Figure 1B) $(5,8,21)$. For this effect, $m i R-126$ may work through directly targeting sprouty-related Drosophilia enabled/vasodilator-stimulator phosphoprotein homology 1 (EVH1) domain-containing protein 1 (SPRED-1), VCAM1, and phosphoinositide-3-kinase, regulatory subunit 2 (PIK3R2 also known as p85- $\beta)(5,9,21,22)$.

Regarding glioblastoma carcinogenesis, it remains controversial as to whether $m i R-126$ is a tumor-suppressive or oncogenic miRNA, depending on the oncological status of the cells $(e . g$. cancer stem cell versus regular cancer cells; see below for more details). A study comparing the expression of $m i R-126$ in oligodendroglioma and astrocytoma (24 patients: two WHO grade II and 22 WHO grade III) found that astrocytomas expressed less $m i R-126$ than oligodendrogliomas (fold change $=0.479)$ (23). Lately, $m i R-126, m i R-137$ and $m i R$ 128 were found to be most overexpressed in non-differentiated glioblastoma spheroid cultures containing stem cell-like tumor 
initiation cells compared to orthotopic xenografts (24). Furthermore, $m i R-126$ was reported to be able to preserve quiescence and stemness of acute myeloid leukemia stem cells via the phosphatidylinositol 3-kinase (PI3K)/a serine/threonine kinase/mammalian target of rapamycin signaling pathway (25). Considering that cancer cell stemness capacity may be a transient oncological property (26), the emerging data suggests that while $m i R-126$ may play a crucial role in preserving stemness capability of cancer initiation cells, it could also suppress general tumor growth by inhibiting angiogenesis inside the neoplasm mass. Mathematical modeling indicated that such raid overall growth could come at a cost of cancer stem cell survival for a particular tumor (27). Future studies should specifically investigate each of the aforementioned mechanisms.

In this study, glioblastomas were found in the frontal, central, and parietotemporal lobe and the size of the tumors ranged from 4.4-6.6 cm. We found that decreased content of $m i R-126$ in glioblastoma was not statistically associated with gender, age, pre-surgery KPS, neoplasm size, nor tumor location, which was similar to an earlier report showing that the expression level of $m i R-210$ was not associated with tumor location (28). In patients with glioblastoma receiving postoperative radiotherapy and chemotherapy, the most frequently reported predictive variables included patient age, performance status, and surgical resection extent. Predictive variables that have been less frequently reported were tumor size and corticosteroid therapy (29). To the best of our knowledge, the present study is the first to investigate the expression ratio of $m i R-126$ intra-glioblastoma versus the peritumoral non-cancerous tissue. Our preliminary results suggest that down-regulation of $m i R-126$ inside the glioblastoma mass may have a possible negative prognostic role in post gross total resection survival of patients with primary glioblastoma.

There are several limitations to this pilot study: i) This was a single hospital-based study which had a small sample size.

ii) Our data may not be sufficient to validate an absolute decrease in expression of $m i R-126$ in intra-glioblastoma tissue due to the fact that we did not control for the exact volume of necrotic tissue inside each tumor for its potential impact, albeit that the gross pathology quality of the tumors appeared comparable. iii) The expression ratio was calculated based on expression of one reference gene only. iv) Although peritumoral normal brain tissues might not have had microscopic evidence of tumor cells, the parenchymal cells might already have been biologically abnormal under the influence of soluble factors related to the tumoral environment. v) Another weakness of the present study resides in the restrictions attributable to the essential features of glioblastoma pathology and resection procedure. Briefly, in order to maximize sparing of brain function and avoid unnecessary injury, only very small pieces of peritumoral brain tissue were collected from the brain surface, $3 \mathrm{~cm}$ from the tumor margin. The peritumoral tissues were therefore not collected from identical locations and their potentially heterogeneous features might have increased sample variability. vi) For a pilot study, we did not assess possible associations between the expression level of $m i R-126$ and other signaling molecules with known roles in mitosis and oncogenesis [e.g. CRK, VCAM1, and sex determining region Y-box 2 (SOX2)]. Therefore, future studies should utilize larger patient samples or well-established glioblastoma cell lines under designs with sufficient statistical powers for each targeted outcome measure in order to draw more definitive correlations regarding the roles of intraglioblastoma expression level of miR-126 in predicting postsurgical prognosis and other glioblastoma oncological profiles.

In conclusion, our preliminary data show that $m i R-126$ may be down-regulated in human primary glioblastomas; patients with a higher ratio of $m i R-126$ expression between the intra-tumoral mass and the peritumoral tissue may have better survival following gross total resection and standard radiochemotherapy compared to patients with lower $m i R$ 126 expression ratio. However, additional systematically designed studies are required to specifically determine the multifaceted roles of miR-126 in glioblastoma carcinogenesis, diagnosis, and prognosis, as well as to identify its target genes in order to further improve the field's understanding of glioblastoma pathology for developing more efficacious therapies.

\section{Funding}

This work was mainly supported by the Korea Healthcare Technology Research \& Development Project, Ministry for Health \& Welfare Affairs, Republic of Korea (HI12C1809, HI14C3270, HI14C3245) and a National Research Foundation of Korea (NRF) Grant, funded by the Korean Government (NRF-2014R1A1A2059118). Work at Teng Laboratories was supported by SCIRP-DoD, CASIS-NASA, HMS and SRH Gordon Project to Cure Clinical Paralysis, and VAR\&D.

\section{Conflicts of Interest}

The Authors declared that there is no conflict of interest in regard to this study.

\section{References}

1 Rivera-Díaz M, Miranda-Román MA, Soto D, Quintero-Aguilo M, Ortiz-Zuazaga H, Marcos-Martinez MJ and Vivas-Mejía PE: MicroRNA-27a distinguishes glioblastoma multiforme from diffuse and anaplastic astrocytoma and has prognostic value. Am J Cancer Res 5: 201-218, 2014.

2 Chen L and Kang C: miRNA interventions serve as 'magic bullets' in the reversal of glioblastoma hallmarks. Oncotarget 6(36): 38628-38642, 2015. 
3 Areeb Z, Stylli SS, Koldej R, Ritchie DS, Siegal T, Morokoff AP, Kaye AH and Luwor RB: MicroRNA as potential biomarkers in glioblastoma. J Neurooncol 125(2): 237-248, 2015.

4 Bello L, Giussani C, Carrabba G, Pluderi M, Costa F and Bikfalvi A: Angiogenesis and invasion in gliomas. Cancer Treat Res 117: 263-284, 2004.

5 Wang S, Aurora AB, Johnson BA, Qi X, McAnally J, Hill JA, Richardson JA, Bassel-Duby R and Olson EN: The endothelialspecific microRNA $m i R-126$ governs vascular integrity and angiogenesis. Dev Cell 15: 261-271, 2008.

6 Yang C, Hou C, Zhang H, Wang D, Ma Y, Zhang Y, Xu X, Bi Z and Geng S: $m i R-126$ functions as a tumor suppressor in osteosarcoma by targeting SOX2. Int J Mol Sci 15: 423-437, 2013.

7 Ebrahimi F, Gopalan V, Smith RA and Lam AK: miR-126 in human cancers: clinical roles and current perspectives. Exp Mol Pathol 96: 98-107, 2014

8 Feng R, Chen X, Yu Y, Su L, Yu B, Li J, Cai Q, Yan M, Liu B and Zhu Z: $m i R-126$ functions as a tumor suppressor in human gastric cancer. Cancer Lett 298: 50-63, 2010.

9 Donnem T, Lonvik K, Eklo K, Berg T, Sorbye SW, Al-Shibli K, Al-Saad S, Andersen S, Stenvold H, Bremnes RM and Busund LT: Independent and tissue-specific prognostic impact of $m i R$ 126 in nonsmall cell lung cancer: coexpression with vascular endothelial growth factor-A predicts poor survival. Cancer 117: 3193-3200, 2011

10 Yang Y, Song KL, Chang H and Chen L: Decreased expression of microRNA-126 is associated with poor prognosis in patients with cervical cancer. Diagn Pathol 9: 220, 2014.

11 Louis DN, Perry A, Reifenberger G, von Deimling A, FigarellaBranger D, Cavenee WK, Ohgaki H, Wiestler OD, Kleihues P and Ellison DW: The 2016 World Health Organization Classification of Tumors of the Central Nervous System: a summary. Acta Neuropathol 31(6): 803-820, 2016.

12 Wong HK, Fatimy RE, Onodera C, Wei Z, Yi M, Mohan A, Gowrisankaran S, Karmali P, Marcusson E, Wakimoto H, Stephens R, Uhlmann EJ, Song JS, Tannous B and Krichevsky AM: The Cancer Genome Atlas Analysis predicts microRNA for targeting cancer growth and vascularization in glioblastoma. Mol Ther 23: 1234-1247, 2015

13 Srinivasan S, Patric IR and Somasundaram K: A ten-microRNA expression signature predicts survival in glioblastoma. PLoS One 6: e17438, 2011

14 Kim H, Huang W, Jiang X, Pennicooke B, Park PJ and Johnson $\mathrm{MD}$ : Integrative genome analysis reveals an oncomir/oncogene cluster regulating glioblastoma survivorship. Proc Natl Acad Sci USA 107: 2183-2188, 2010.

$15 \mathrm{Li} \mathrm{Y,} \mathrm{Li} \mathrm{Y,} \mathrm{Ge} \mathrm{P} \mathrm{and} \mathrm{Ma} \mathrm{C:} \mathrm{mir-126} \mathrm{Regulates} \mathrm{the} \mathrm{ERK} \mathrm{pathway}$ via targeting KRAS to inhibit glioma cell proliferation and invasion. Mol Neurobiol doi: 10.1007/s12035-015-9654-8, 2016.

16 Nicoli S1, Standley C, Walker P, Hurlstone A, Fogarty KE and Lawson ND: MircroRNA-mediated integration of hemodynamics and VEGF signaling during angiogenesis. Nature 464: 1196-1200, 2010.

17 Guo C, Sah JF, Beard L, Willson JK, Markowitz SD and Guda $\mathrm{K}$ : The noncoding RNA, $m i R-126$, suppresses the growth of neoplastic cells by targeting phosphatidylinositol 3-kinase signaling and is frequently lost in colon cancers. Genes Chromosomes Cancer 47: 939-946, 2008.
18 Otsubo T, Akiyama Y, Hashimoto Y, Shimada S, Goto K and Yuasa Y: MicroRNA-126 inhibits SOX2 expression and contributes to gastric carcinogenesis. PLoS One 6: e16617, 2011.

19 Zhang J, Du YY, Lin YF, Chen YT, Yang L, Wang HJ and Ma D: The cell growth suppressor, miR-126, targets IRS-1. Biochem Biophys Res Commun 377: 136-140, 2008.

20 Liu B, Peng XC, Zheng XL, Wang J and Qin YW: MiR-126 restoration down-regulates $V E G F$ and inhibits the growth of lung cancer cell lines in vitro and in vivo. Lung Cancer 66: 169-175, 2009.

21 Fish JE, Santoro MM, Morton SU, Yu S, Yeh RF, Wythe JD, Ivey KN, Bruneau BG, Stainier DY and Srivastava D: $m i R-126$ regulates angiogenic signaling and vascular integrity. Dev Cell 15: 272-284, 2008

22 Wang L, Tabu K, Kimura T, Tsuda M, Linghu H, Tanino M, Kaneko S, Nishihara $\mathrm{H}$, and Tanaka S: Signaling adaptor protein CRK is indispensable for malignant feature of glioblastoma cell line KMG4. Biochem Biophys Res Commun 362: 976-981, 2007.

23 Gonda DD, Cheung VJ, Muller KA, Goyal A, Carter BS and Chen CC: The Cancer Genome Atlas expression profiles of lowgrade gliomas. Neurosurgical Focus 36: E23, 2014.

24 Halle B, Thomassen M, Venkatesan R, Kaimal V, Marcusson EG, Munthe S, Sørensen MD, Aaberg-Jessen C, Jensen SS, Meyer M, Kruse TA, Christiansen H, Schmidt S, Mollenhauer J, Schulz MK, Andersen C and Kristensen BW: Shift of microRNA profile upon orthotopic xenografting of glioblastoma spheroid cultures. J Neurooncol 128: 395-404, 2016.

25 Lechman ER, Gentner B, Ng SW, Schoof EM, van Galen P, Kennedy JA, Nucera S, Ciceri F, Kaufmann KB, Takayama N, Dobson SM, Trotman-Grant A, Krivdova G, Elzinga J, Mitchell A, Nilsson B, Hermans KG, Eppert K, Marke R, Isserlin R, Voisin V, Bader GD, Zandstra PW, Golub TR, Ebert BL, Lu J, Minden M, Wang JC, Naldini L and Dick JE: $m i R-126$ regulates distinct self-renewal outcomes in normal and malignant hematopoietic stem cells. Cancer Cell 29: 602-606, 2016.

26 Zeng X, Han I, Abd-El-Barr M, Aljuboori Z, Anderson JE, Chi JH, Zafonte RD and Teng YD: The effects of thermal precondition on oncogenic and intraspinal cord growth features of human glioma cells. Cell Transplant doi: 10.3727/096368916X691493, 2016.

27 Poleszczuk J, Hahnfeldt P and Enderling H: Evolution and phenotypic selection of cancer stem cells. PLoS Comput Biol 11: e1004025, 2015.

28 Li C, Zhou X, Wang Y, Jing S, Yang C, Sun G, Liu Q, Cheng Y, Wang L: miR-210 regulates esophageal cancer cell proliferation by inducing $\mathrm{G}_{2} / \mathrm{M}$ phase cell cycle arrest through targeting PLK1. Mol Med Rep 10: 2099-2104, 2014.

29 Michaelsen SR, Christensen IJ, Grunnet K, Stockhausen MT, Broholm H, Kosteljanetz M and Poulsen HS: Clinical variables serve as prognostic factors in a model for survival from glioblastoma multiforme: an observational study of a cohort of consecutive non-selected patients from a single institution. BMC Cancer 13: 402, 2013.
Received October 6, 2016

Revised October 13, 2016

Accepted November 11, 2016 